\title{
Electrochemical Mechanism of Microporous Autocatalytic Surface Formation on a High-Chromium Alloy in an Alkaline Solution
}

\author{
Fulin Zhang ${ }^{1}$, Zhuji Jin ${ }^{1, *}$, Lida Wang ${ }^{2}$, Guannan Jiang ${ }^{1}$, Junmin Pei ${ }^{1}$ \\ ${ }^{1}$ Key Laboratory for Precision and Non-Traditional Machining Technology of Ministry of Education, \\ Dalian University of Technology, Dalian 116024, PR China \\ ${ }^{2}$ Department of Chemical Engineering, School of Chemical Engineering, Dalian University of \\ Technology, Dalian 116024, PR China \\ *E-mail: kimsg@,dlut.edu.cn
}

doi: $10.20964 / 2020.10 .60$

Received: 25 June 2020 / Accepted: 13 August 2020 / Published: 31 August 2020

\begin{abstract}
An experimental and analytical investigation of the formation of a microporous layer of mixed ferric oxide and ferric hydroxide on a high-chromium alloy in alkaline solution under the oxygen evolution region is presented. By potentiostatic polarization under $5 \mathrm{~V}_{\mathrm{Ag} / \mathrm{AgCl}}$, a dark red microporous layer was formed on the surface of the high-chromium alloy. The workpieces and electrolytes were examined and analyzed by scanning electron microscopy (SEM), X-ray fluorescence (XRF), Raman microscopy (RMS) and inductively coupled plasma (ICP) to probe the electrochemical mechanism of layer formation. The results demonstrate that under the set conditions, $\mathrm{Fe}(\mathrm{VI})$ ions were generated from the anode. However, due to the consumption of $\mathrm{OH}^{-}$ions, $\mathrm{Fe}(\mathrm{VI})$ ions were decomposed into ferric hydroxide; in turn, ferric hydroxide had an autocatalytic effect on the decomposition of $\mathrm{Fe}(\mathrm{VI})$ ions. The anodic reaction steps were controlled by the mass transfer of $\mathrm{OH}^{-}$ions, and alternative transformation between $\mathrm{Fe}(\mathrm{VI})$ ions and ferric hydroxide accelerated the formation of a microporous layer.
\end{abstract}

Keywords: High-chromium alloy; Autocatalytic effect; Anodic reactions; Electrochemical deposition

\section{$\underline{\text { FULL TEXT }}$}

(C) 2020 The Authors. Published by ESG (www.electrochemsci.org). This article is an open access article distributed under the terms and conditions of the Creative Commons Attribution license (http://creativecommons.org/licenses/by/4.0/). 